\title{
El yihad y el tratamiento de la guerra en el Corán
}

\author{
The jihad and the treatment of war in the Qur'an
}

\author{
Juan Luis de León Azcárate \\ Facultad de Teología de la Universidad de Deusto \\ jleon@deusto.es
}

Sumario: Introducción. 1. El concepto de yihad y las aleyas «pacifistas» y «belicistas» del Corán. 1.1. El concepto de yihad en el Corán. 1.2. Aleyas «pacifistas». 1.3. Aleyas contra las reticencias a combatir. 1.4. Aleyas «belicistas». 2. Prescripciones coránicas sobre la guerra. 2.1. Causas que legitiman el combate. 2.2. Normas para el combate. Reflexiones conclusivas. Bibliografía.

Resumen: El presente estudio analiza el sentido que tiene el concepto de yihad en el Corán, el principal texto fundacional del islam, y el tratamiento que hace de la violencia y la guerra. El estudio enfatiza la necesidad de comprender los textos fundacionales considerados sagrados atendiendo al contexto histórico en el que surgieron, y concluye que los preceptos coránicos sobre el yihad y la guerra participan de un humanitarismo de inspiración religiosa que difiere plenamente de las prácticas del terrorismo yihadista.

Palabras clave: Corán, islam, yihad, terrorismo, violencia.

Abstract: The present study analyzes the meaning of the concept of jihad in the Qur'an, the main foundational text of Islam, and its treatment of violence and war. The study emphasizes the need to understand the foundational texts considered sacred, taking into account the historical context in which they arose, and concludes that the quranic rules on jihad and war participate in a religious-inspired humanitarianism that differs fully from the practices of jihadist terrorism.

Keywords: Qur'an, Islam, jihad, terrorism, violence. 


\section{Introducción}

Si hay una religión que, lamentablemente, hoy día está vinculada en el imaginario popular occidental con la violencia, esa es el islam. Esto se debe principalmente a las acciones terroristas que diversos grupos islamistas están llevando a cabo desde hace décadas en gran parte de la geografía mundial y que tantas víctimas provocan, la mayoría musulmanas. Pero también se debe al gran desconocimiento de una religión sobre la que todavía en Occidente pesan muchos prejuicios alimentados por una historia de conflictos bélicos y choques culturales. El presente trabajo pretende mostrar que la concepción del yihad y las pautas de guerra recogidas en el principal texto fundacional del islam, el Corán, están imbuidas de un profundo humanitarismo de inspiración religiosa que limita los excesos de la guerra y contradice las prácticas de los grupos terroristas yihadistas.

Resulta paradójico que muchos de los miembros de estos grupos tengan un conocimiento muy precario de la religión que dicen profesar, como muestra el informe Estado Islámico en España del Real Instituto Elcano, elaborado por Fernando Reinares y Carola García-Calvo:

"Ya se trate de musulmanes de origen o de conversos, ¿qué grado de conocimiento del islam y de la sharía o ley islámica cabe atribuir a los detenidos en España desde 2013 por actividades terroristas relacionadas con El? Nuestra estimación, considerando la limitada información disponible al respecto, es que sólo para un $11 \%$ de los casos cabe apreciar un conocimiento relevante de ese credo religioso y de su ley, en tanto que se trataría de un conocimiento elemental para el restante 89\%» (Reinares y García-Calvo 2016, 30).

El Corán («recitación») es el libro sagrado de los musulmanes y la primera de sus fuentes de derecho. Su texto es uno y el mismo para todos los musulmanes, sea cual sea su filiación confesional: suní, chiita o jariyí. Para entender las aleyas o versículos relativos a la violencia y a la guerra hay que contextualizarlos en la biografía de Mahoma, la cual se suele dividir en dos períodos separados por la hégira o emigración del 622 d.C. ${ }^{1}$. Una primera etapa en la que vivió en La Meca (612622 d.C.), período mequí o mecano, y una segunda etapa en la que vivió en Medina hasta su muerte (622-632 d.C.). Las tradiciones

1 El calendario musulmán comienza a contabilizarse a partir de la hégira, de modo que en adelante señalaré la cronología indicando, a la par, el año musulmán (con H, de hégira) y el occidental de la era cristiana. 
cronológicas musulmanas consideran que veinticuatro o veintisiete de las ciento catorce suras o capítulos que forman el Corán fueron reveladas a Mahoma durante el período medinense y el resto durante el mecano. Durante este período, predominan las aleyas de carácter más pacífico y humanitario, mostrando a un Dios de naturaleza justa (cf. Corán 16, 125-126). Sin embargo, tras su expulsión de La Meca y refugiarse en Medina, Mahoma crea un Estado musulmán con resortes para defenderse tanto de los enemigos internos como de los externos, aunque el Corán no indica referencia alguna a cómo fue este estado u organización política ni a cómo debía serlo en el futuro. La nueva comunidad o umma parte de una concepción religiosa de «hermandad» (mu'akhat) que pretende superar los tradicionales lazos tribales y de sangre (cf. Corán 3,103), algo que no fue fácil asimilar. Con todo, durante este período se calcula, si bien las fuentes varían en las cifras, que Mahoma participó en al menos veintisiete campañas guerreras y colaboró de alguna forma en otras cincuenta y nueve? Todas ellas pueden dividirse en cinco grupos ${ }^{3}$ :

- Las cinco batallas principales de Badr (2 H/624 d.C.), Uhud (3 H/625 d.C.) Khandaq (5 H/627 d.C.), La Meca (8 H/630 d.C.) y Hunayn $(8 \mathrm{H} / 630$ d.C.), con el objetivo de dominar las tres principales áreas asentadas de la Hijaz: La Meca, Medina y alTa'if.

- Incursiones contra los beduinos, para forzar a las tribus locales a que apoyen o al menos no ataquen a los musulmanes.

- Ataques contra las tribus judías para garantizar los oasis en los cuales ellos residían.

2 La sira o vida de Mahoma escrita por Ibn Ishaq (Guillaume 2015, 359-361), fallecido hacia 150 H/767 d.C., ofrece una lista completa de estas campañas. También cabe destacar la obra biográfica sobre Mahoma de Al-Waqidi (fallecido hacia 207H/823 d.C.), que es sobre todo un relato de las expediciones e incursiones militares llevadas a cabo por el Profeta (Faizer 2011). Por su parte, (Khadduri 1955, 87, nota 25) señala que Mahoma comandó veintiséis o veintisiete de las cincuenta y cinco expediciones militares que la comunidad musulmana realizó a lo largo de la vida del Profeta. En Sahîh Muslim, n. ${ }^{\circ}$ 4467, una de las colecciones de hadices (dichos o hechos atribuidos a Mahoma por la tradición o sunna) más importantes y que data del siglo Ix d.C., se dice que Mahoma participó en diecinueve batallas y peleó personalmente en ocho de ellas. Actualmente algunos autores discuten la veracidad histórica de estas biografías de Mahoma, pero, más allá del dato histórico, lo que aquí interesa es que las fuentes musulmanas coinciden en que Mahoma participó en diversas campañas, algo que aceptan unánimemente los musulmanes, razón por la que este dato se convierte en relevante.

3 Cf. (Cook 2015, 6). 
- Dos incursiones en al-Mu'ta (7 H/629 d.C.) y Tabuk (9 H/631 d.C.) y la campaña liderada por Osama b. Zayd (10 H/632 d.C.) contra Siria, que, aunque no muy exitosa, anunció la dirección de las conquistas musulmanas durante los años siguientes a la muerte del Profeta en $10 \mathrm{H} / 632$ d.C.

Dado este contexto se entiende que las suras medinenses muestren un tono más beligerante y justificativo de la guerra contra los infieles. Para superar esta aparente antinomia entre aleyas pacifistas y belicistas, los antiguos sabios musulmanes, basándose en Corán 2,106, se sirvieron del concepto de naskh («abrogación») afirmando que las aleyas reveladas posteriormente excluían o abrogaban, a efectos de la sharía, las aleyas anteriores, dado que se entendía que éstas se referían a un estado superado de la comunidad musulmana. Esto daría, en principio, una cierta preeminencia a las suras y aleyas del período medinense, de carácter más belicoso. Sin embargo, los exégetas no se ponen de acuerdo sobre las fechas de las revelaciones, imprescindibles para conocer el contexto de las revelaciones y deducir de ellas consecuentemente su amplitud y su grado de perennidad. Esto dificulta determinar con exactitud cuáles son las aleyas «abrogantes» y cuáles las «abrogadas» ${ }^{4}$. No obstante, autores recientes, siguiendo este mismo principio de la abrogación, consideran que hoy sería posible invertir el procedimiento de abrogación con vistas a desarrollar una versión moderna de la sharía y del islam, dando preeminencia a las suras y aleyas mequíes, más pacíficas y humanitarias, con el fin de garantizar la igualdad para las mujeres y los no musulmanes ${ }^{5}$.

\section{El concepto de yihad y las aleyas "pacifistas» $y$ «belicistas» del Corán}

\subsection{Concepto de yihad en el Corán}

El concepto de yihad, como otras palabras tomadas de un contexto religioso, tiene una larga historia y, por esto mismo, abarca un complejo elenco de significados. La traducción, muy generalizada a

4 Como señala Flori (2004, 87-88).Véase también Hallaq (2009, 92-97).

5 Tal es el caso, por ejemplo, de An-Na'im (1990, 239-249), quien en este punto sigue al reformador musulmán sudanés Ustadh Mahmoud Mohamed Taba. Lamentablemente, Taba, por defender esta idea, fue condenado a muerte y ejecutado en Sudán, en 1985, acusado de apostasía (cf. Borreguero 2004, 157). 
nivel popular, de "guerra santa» ${ }^{6}$ no es la más adecuada en la mayoría de los casos en los que aparece en el Corán. Este término masculino 7 deriva de la raíz arábiga jahada, que significa «esforzarse» o "forzarse a sí mismo» hacia algún objetivo. En sentido amplio, en el contexto de las aleyas coránicas, puede traducirse por «esfuerzo realizado en la vía de Alá». Así, por ejemplo, se habla del yihad del corazón, la lucha con uno mismo por mejorar como ser humano, o el yihad de la lengua (Corán 3, 110, 114; 9, 7), el esfuerzo por legislar u opinar justamente, y otros $^{8}$. La siguiente aleya medinesa mantiene este carácter no bélico y exclusivamente religioso:

«jLuchad por Dios como Él se merece! Él os eligió y no os ha impuesto ninguna carga en la religión. ¡La religión de vuestro padre Abraham! Él os llamó "musulmanes" anteriormente y aquí, para que el Enviado sea testigo de vosotros y que vosotros seáis testigos de los hombres. ¡Haced la azalá y dad el azaque! ¡Y aferraos a Dios! ¡Él es vuestro Protector! ¡Es un protector excelente, un auxiliar excelente!» (Corán 22, 78) .

En el Corán el término yihad y sus derivaciones aparecen en cuarenta y una ocasiones ${ }^{10}$. En veintidós de ellas en un sentido general

6 En sentido estricto, en árabe "guerra santa» se diría al-harb al-muqaddas, pero esta expresión no existe de ninguna manera en la tradición islámica.

7 Como señala López Pita $(2009,149)$, razón por la que es preferible hablar de «el yihad» y no de "la yihad» que invita a pensar más en «la lucha» O «la guerra santa».

8 Paradela (2001, 653-667), siguiendo a Peters (1979), señala las siguientes clases de yihad: a) El yihad del corazón: Se trata del combate espiritual o yihad mayor. b) El yihad de la lengua: Consiste en opinar o legislar justamente. La expresión clásica lo dice así: "Ordenar lo que es bueno y prohibir lo que es malo». c) El yihad de la mano: Consiste en poner en práctica medidas correctivas o punitivas para evitar que los creyentes cometan actos sancionables. d) El yihad del dinero: Así se denomina el hecho de contribuir económicamente a las necesidades de la umma. e) El yihad de la predicación: Implica toda acción pacífica destinada a extender el islam fuera de sus fronteras o a su fortalecimiento en el interior. f) El yihad de la espada: Significa llevar a cabo una acción armada destinada a proteger las tierras del islam y la propia supervivencia del islam en ellas. Por otro lado, y atendiendo a las interpretaciones de los juristas musulmanes, Khadduri $(1955,74-82)$ señala los siguientes tipos de yihad: el yihad contra los politeístas, el yihad contra la apostasía, el yihad contra los intentos de disensión (baghi), el yihad contra los desertores y el bandidaje, el yihad contra la gente de la Escritura y el yihad para salvaguardar las fronteras (ribat).

9 Para el Corán sigo en todo momento la traducción de Cortés (1992). El lector de habla española dispone también de otras buenas traducciones como las de Venet (2010) y Huech (2017).

10 Cf. Landau-Tasseron (2003, 35). 
y tres para referirse a un acto puramente espiritual ${ }^{11}$. Los otros diez casos, en cambio y como se verá más adelante, se refieren a una acción guerrera. El propio término yihad sólo aparece en cuatro ocasiones (Corán 9, 24; 22, 78; 25, 52; 47, 31). Para referirse al hecho de luchar con armas, el Corán utiliza qital («combatir») y sus derivaciones. La palabra «guerra» (harb) aparece en el Corán únicamente seis veces ${ }^{12}$. La palabra "paz» (salam) lo hace unas cuarenta ocasiones, aunque la mayoría de ellas de manera vaga refiriéndose a estar en paz con Dios (Donner 2007, 299) ${ }^{13}$. Sin embargo, aparece hasta ciento sesenta veces el verbo qatala que significa «matar», "luchar», "combatir», y, aunque la mayor parte de las veces se refiere a episodios bíblicos ${ }^{14}$, en diecinueve ocasiones es dando orden de combatir, guerrear y/o matar $^{15}$. Esto significa que, si bien la doctrina del yihad guerrero no está claramente expresada en el Corán y no será desarrollada y codificada hasta el siglo Ix d.C. con el fin de justificar las conquistas árabes y el imperio musulmán, las raíces de una normativa relativa a la organización de la actividad bélica ya se encontraban de alguna forma en él. Sin embargo, conviene apuntar que la distinción que hoy día se hace entre el "yihad mayor» o yihad akbar, entendido como el combate moral o lucha espiritual que lleva a cabo el musulmán como individuo en el camino de Alá, y el «yihad menor» o yihad asghar, propiamente la guerra santa o guerra defensiva contra los enemigos del islam a la que está obligada la comunidad musulmana, no aparece

11 Básicamente, como señala Heck $(2004,98)$, en el Corán el término yihad no señala una actividad militar per se sino una causa recta o justa ante Dios.

12 Corán 2, 279; 5, 33; 64; 8, 57; 9, 107; 47, 4. Rippin (2016, 33-48), tras analizar dos textos antiguos que ponen su atención en aspectos legales del Corán, el Tafsir alKhams Mi'atAya min al-Qur'an al-Karim de Muqatil b. Sulayman (fallecido el 150 H/767 d.C.) y el Kitab al-Nasikhwa-l-mansukh de Abu 'Ubayd (fallecido el 223 H/838 d.C.), concluye, entre otros aspectos, que en ambas obras no hay distinción entre yihad y qital ni tampoco sugerencia alguna de que haya diferentes tipos de yihad o que este término tenga otro sentido que el conectado con la guerra o que pueda entenderse con algún tipo de genérico "esfuerzo». El sentido de «lucha», qital, es consistente. Según este autor, podría decirse que el yihad ha llegado a ser el término islamizado del secular qital.

13 Como señalan Arendonk y Gimaret $(1995,915)$, salam es el nombre verbal de salima, "estar seguro, ileso», y usado como sustantivo significa "seguridad, salvación», y de aquí «paz».

14 Esto no significa necesariamente que las tradiciones bíblicas sean el mejor referente para entender el concepto de guerra santa en el Corán. Como señala Firestone $(1999,19)$, las costumbres, rituales y conceptos culturales y religiosos de la Arabia pre-islámica son fundamentales en este sentido.

15 Entre ellas, Corán 2, 216. 244; 4, 74; 9, 29; 49, 9. Datos ofrecidos por Catalá $(2010,65)$. 
propiamente en el Corán sino en la literatura posterior, particularmente a partir del siglo XI d.C. ${ }^{16}$.

Si se atiende al hipotético contexto histórico en el que pudieron haberse escrito (esto es, si lo fueron durante el período previo a la hégira o durante el período medinense) y a su contenido (pro o antibelicista), pueden encontrarse en el Corán al menos tres grupos distintos de aleyas relativas a la actitud que debe guardarse hacia los no creyentes ${ }^{17}$. Estos grupos son: las aleyas "pacifistas», las aleyas contra las reticencias a combatir y las aleyas «belicistas».

\subsection{Aleyas «pacifistas»}

Las aleyas «pacifistas» son ocho (Corán 6,$106 ; 15,94 ; 16,125-$ 127; 50, 39). Cuatro de ellas correspondientes al período mequí, cuando los musulmanes o creyentes $^{18}$ se encontraban en una posición

16 Cf. Fine $(2015,112)$. Cook $(2015,35-39)$ señala que las tradiciones acerca del yihad entendido como lucha espiritual están ausentes de las colecciones canónicas oficiales, con la excepción de al-Tirmidhi, quien afirma que «el luchador es quien combate sus pasiones» ( $\left.n .^{\circ} .1671\right)$, aunque lo hace en el contexto de la murabit o lucha por defender las fronteras. Cook también señala que, aunque algunos hadices del siglo Ix d.C. ya aluden a ella, los verdaderos comienzos del concepto de "yihad mayor» se remontan al gran teólogo sufí al-Ghazali (muerto hacia el 1111 d.C.) en su gran obra Ihya 'ulum al-din (Renacimiento de las ciencias religiosas), donde reinterpreta la aleya del Corán 4,95 en sentido de que los musulmanes no deben luchar por causa de sus posesiones y personas sino contra sus propias pasiones y por sus almas. Pero al-Ghazali no indica en ningún lugar de su obra que considere el yihad contra el alma como un sustituto del yihad militante. Y lo mismo podría decirse de otros maestros sufís que distinguen entre ambos tipos de yihad.

17 Firestone $(1999,69-91)$ clasifica en cuatro grupos los versos coránicos relativos a la guerra: los que expresan medios de propagación o defensa de la fe no militaristas, los que expresan restricciones en la lucha, los que expresan conflicto entre el mandato divino y la reacción de los seguidores de Mahoma, y los que defienden con firmeza la guerra por la religión de Dios. Flori $(2004,87-96)$ también distingue cuatro grupos principales: las aleyas "pacifistas», las que refutan las reticencias ante la lucha armada, las que revelan una resistencia de algunos creyentes hacia la orden de combatir dada por Dios y las que prescriben claramente el uso de la fuerza armada por la causa de Dios (yihad guerrera). Por su parte, Gutiérrez (2009, 193-195) reduce los cuatro grupos propuestos por Flori a tres: las aleyas pacifistas (Corán 6, 106; 15, 94; 16, 127 y 50, 39), las aleyas contra las reticencias a la guerra (Corán 2, 190-191, 194, 218; 3, 165-169; 4, 66-97; 9, 36; 33, 13-25) y las aleyas belicistas (Corán, 2, 190-195). En mi opinión, el grupo segundo y tercero propuestos por Flori bien podrían integrarse en uno solo; opción que tomo en este trabajo.

18 Donner (2002-2003) considera que Mahoma y sus primeros seguidores en un primer momento se vieron a sí mismos como una "comunidad de creyentes» (mu'minun) que creían en un único Dios, en la inminencia del Juicio Final y en la 
difícil entre sus propias tribus vistas por ellos como idólatras. Estas aleyas recomendaban evitar el trato con los idólatras o "asociadores» (mushrikeen), así llamados porque asociaban al Dios verdadero con otros dioses, presentar prudentemente su fe y mostrar paciencia. Por ejemplo:

«Sigue lo que se te ha revelado, procedente de tu Señor. No hay más dios que Él. Y apártate de los asociadores» (Corán 6, 106).

«Llama al camino de tu Señor con sabiduría y buena exhortación. Discute con ellos de la manera más conveniente. Tu Señor conoce mejor que nadie a quien se extravía de su camino y conoce mejor que nadie a quien está bien dirigido. Si castigáis, castigad de la misma manera que se os ha castigado. Pero, si tenéis paciencia, es mejor para vosotros. ¡Ten paciencia! No podrás tener paciencia sino con la ayuda de Dios. Y no estés triste por ellos, ni te angusties por sus intrigas» (Corán 16, 125-127).

Las otras cuatro pertenecen al período medinense cuando Mahoma se había aliado con varias tribus judías esperando su conversión. Éstas apelan a la paciencia, tolerancia y perdón. Será el propio Alá quien se encargue de castigar a los infieles el Día del Juicio (Corán 2, 115-137; 5, 10; 29, 46-55; 42, 16). Así:

«Decid: "Creemos en Dios y en lo que se nos ha revelado, en lo que se reveló a Abraham, Ismael, Isaac, Jacob y las tribus, en lo que Moisés, Jesús y los profetas recibieron de su Señor. No hacemos distinción entre ninguno de ellos y nos sometemos a Él". Así, pues, si creen en lo mismo que vosotros creéis, estarán en la vía recta. Pero si se desvían, estarán entonces en oposición. Dios te bastará contra ellos. Él es Quien todo lo oye. Quien todo lo sabe"» (Corán 2, 136137).

«Quienes no crean y desmientan Nuestros signos morarán en el fuego de la gehena» (Corán 5, 10).

Por tanto, la única violencia que cabe en estos casos es la que podría denominarse como «violencia escatológica», ejercida

necesidad de restaurar la justicia en la tierra. Esta comunidad estaba abierta a algunos judíos, cristianos y otros monoteístas, y sólo los «asociadores» (mushrikun) o politeístas quedaban fuera de ella. Más tarde, particularmente en el período de las conquistas, y a través de un proceso todavía pendiente de clarificar, la «comunidad de creyentes» pasó a ser la «comunidad de musulmanes» que se veía a sí misma como una confesión religiosa distinta. 
únicamente por Dios al final de los tiempos, pero no por la umma que debe mostrarse paciente y evitar la confrontación. En este sentido, podría decirse que únicamente Dios tiene la prerrogativa de la violencia.

\subsection{Aleyas contra las reticencias a combatir}

El Corán deja claro, en la siguiente aleya medinesa, que el verdadero musulmán es el que, llegado el caso, está dispuesto a combatir sin dudarlo ${ }^{19}$ :

"Son creyentes únicamente los que creen en Dios y en Su Enviado, sin abrigar ninguna duda, y combaten por Dios con su hacienda y sus personas. ¡Ésos son los veraces!» (Corán 49, 15).

Sin embargo, no faltaron entre las filas de Mahoma quienes, por diversas razones, objetaron el deber de combatir. Las reticencias podían ser de varios tipos y reflejan las tensiones internas por las que pasó la umma. A todas ellas respondió Mahoma20:

a) El rechazo, siguiendo costumbres preislámicas, de combatir durante los «meses sagrados», particularmente el mes de dul-qada, mes de tregua en el que los árabes aprovechaban para sus peregrinaciones y ferias comerciales. Se hizo necesario recurrir a una autoridad superior, divina, que sancionara un proceder que violaba las viejas costumbres tribales (Firestone 1999, 131-132). Varias aleyas (Corán 2,190-191, 194, 217; 9 ,36) pretenden desacralizar estos meses bajo el argumento de que la tentación de la idolatría (fitna) es más grave que el hecho de matar durante ese período. Si los musulmanes son atacados durante dichos meses con el fin de hacerles perder la fe, tienen la obligación de defenderse. En enero de 624 d.C./2 H se produjo la que probablemente fue la primera muerte a manos de un musulmán durante una razia o algazúa contra una

19 Se entiende, además, que combatir por Dios es provechoso para uno mismo: «Quien combate por Dios combate, en realidad, en provecho propio. Dios, ciertamente, puede prescindir de las criaturas» (Corán 29, 6). Más aún, el Corán deja claro que "Los creyentes que se quedan en casa, sin estar impedidos, no son iguales que los que combaten por Dios con su hacienda y sus personas» $(4,95)$.

20 Flori (2004,90-91) a las aleyas que aluden a las reticencias comprendidas entre los apartados b) y e) las denomina aleyas «anti-pacifistas». 
caravana. Este período coincidía con uno de los meses sagrados (el mes de rayab) durante el cual estaba prohibido derramar sangre. Las objeciones jurídicas y rituales que pudieran provocar esta acción fueron resueltas con la siguiente aleya:

«Te preguntan si está permitido combatir en el mes sagrado. Di: "Combatir en ese mes es pecado grave. Pero apartar del camino de Dios - y negarle-y de la Mezquita Sagrada ${ }^{21}$ y expulsar de ella a la gente es aún más grave para Dios, así como tentar es más grave que matar". Si pudieran, no cesarían de combatir contra vosotros hasta conseguir apartaros de vuestra fe. Las obras de aquéllos de vosotros que apostaten de su fe y mueran como infieles serán vanas en la vida de acá y en la otra. Ésos morarán en el Fuego eternamente» (Corán 2, 217).

b) Reticencia a tener que abandonar el hogar para combatir. A ella se responde prometiendo la misericordia divina a quienes abandonen sus hogares para combatir en la senda de Dios:

"Quienes creyeron y quienes dejaron sus hogares, combatiendo esforzadamente por Dios, pueden esperar la misericordia de Dios. Dios es indulgente, misericordioso» (Corán 2, 218).

c) Reticencia a combatir amparándose en una supuesta incompetencia militar para la guerra. El contexto pudo ser la batalla de Uhud (23 de marzo de 625 d.C./3 H), en la que los mequíes derrotaron a Mahoma frente a Medina. Quienes manifiestan tal actitud son considerados cobardes (Corán 3, 155) e incluso hombres de poca fe (Corán 3, 165-169):

"Se les dijo: "¡Vamos! ¡Combatid por Dios o rechazad al enemigo!" Dijeron: "Si supiéramos combatir, os seguiríamos". Aquel día estaban más cerca de la incredulidad que de la fe. Dicen con la boca lo que no tienen en el corazón. Pero Dios sabe bien lo que ocultan» (Corán 3, 167).

La derrota en esta batalla creó serias dudas entre los musulmanes. Tras la victoria inesperada en la batalla de Bard, atribuida a la ayuda divina, ahora se preguntaban cómo era posible que si Dios estuvo con ellos en aquella ocasión por qué habían sido derrotados en Uhud. Incluso corrieron rumores 
de que Mahoma había muerto en esta batalla, aunque sólo fue herido. La respuesta a estas dudas fue que Dios estaba probando a los musulmanes alternando victorias y derrotas, y dejando claro que el islam y su proyecto no terminan con la muerte de Mahoma, quien sólo es un enviado más:

"Si sufrís una herida, otros han sufrido una herida semejante. Nosotros hacemos alternar esos días entre los hombres para que reconozca Dios a quienes crean y tome testigos de entre vosotros -Dios no ama a los impíos-, para que pruebe Dios a los creyentes y extermine a los infieles. O ¿creéis que vais a entrar en el Jardín sin que Dios haya sabido quiénes de vosotros han combatido y quiénes han tenido paciencia? Sí, deseabais la muerte antes de encontrarla. Ya la habéis visto, pues, con vuestros propios ojos. Muhammad no es sino un enviado, antes del cual han pasado otros enviados. Si, pues, muriera o le mataran, ¿ibais a volveros atrás? Quien se vuelva atrás no causará ningún daño a Dios. Y Dios retribuirá a los agradecidos» (Corán 3, 140-144).

En la mencionada sira o vida de Mahoma escrita por Ibn Ishaq se describe detenidamente esta batalla y concluye, en la línea del Corán, que fue una prueba para los creyentes musulmanes:

«El día de Uhud fue un día de juicio, calamidad, y de examen de conciencia en el cual Dios probó a los creyentes y puso a los hipócritas en juicio, quienes profesaban la fe con su lengua y escondían la incredulidad en sus corazones; y un día en que Dios honró con el martirio a los que él quiso» (Ishaq, Sirat Rasûl Alláh, n. $\left.{ }^{0} 592\right)^{22}$.

d) Reticencia a causa de la cantidad de creyentes que mueren en el combate (Corán 3, 168). La respuesta esboza la doctrina del martirio al señalar que quienes mueren en el combate vivían realmente cerca de Dios y recibirán la vida de él (Corán 3, 169; 4, 66-97; cf. 47, 4-6; 61, 10-13), un premio mucho mayor que cualquier botín de guerra.

"Son ellos quienes, mientras se quedaban en casa, decían de sus hermanos: "Si nos hubieran escuchado, no les habrían matado". Di: " ¡Apartad, pues, la muerte de vosotros, si es verdad lo que decís!". Y no penséis que quienes han caído por Dios hayan muerto. ¡Al

22 Sigo la traducción de Guillaume $(2015,391)$. 
contrario! Están vivos y sustentados junto a su Señor» (Corán 3, 168169).

"Quienes creen, combaten por Dios. Quienes no creen, combaten por los taguts. Combatid, pues, contra los amigos del Demonio. ¡Las artimañas del Demonio son débiles! ¿No has visto a aquéllos a quienes se dijo: “¡Deponed las armas! ¡Haced la azalá y dad el azaque!"? Cuando se les prescribe el combate, algunos de ellos tienen tanto miedo de los hombres como deberían tener de Dios, o aún más, y dicen: " ¡Señor! ¿Por qué nos has ordenado combatir? Si nos dejaras para un poco más tarde..." Di: "El breve disfrute de la vida de acá es mezquino. La otra vida es mejor para quien teme a Dios. No se os tratará injustamente en lo más mínimo" » (Corán 4, 76-77).

e) Reticencias a las expediciones militares ordenadas por Mahoma, a veces por miedo (Corán 4, 77; 9, 13; 33, 19), las cuales ciertamente contrastaban con las revelaciones anteriores a la hégira de tono más pacífico. A esto responden algunas aleyas amenazando con el infierno (Corán 9,42-49), y otras recordando las intervenciones divinas precedentes a favor de los creyentes (Corán 3, 123-124; 8, 9. 17; 9, 25; 33, 13-25)23. En particular, se está recordando la batalla de Badr (2 H/624 d.C.), que supuso la primera gran victoria de Mahoma y en la que, se afirma, los musulmanes fueron asistidos por tres mil ángeles, y la rendición de la tribu judía medinesa de los Banu Qurayza tras la «batalla del foso» $(5 \mathrm{H} / 627 \text { d.C. })^{24}$.

23 Este recurso a la evocación de las acciones salvadoras de Alá en el pasado para generar confianza en la victoria ya era utilizado más de mil años antes en la Torá, particularmente en el Deuteronomio, para que los israelitas confiaran en el éxito de la conquista de la Tierra Prometida (cf. Dt 4, 37-40; 7, 8-11; 8, 2-6; 9, 4-7).

24 Esta batalla, así llamada porque Mahoma mandó cavar un foso alrededor de Medina para protegerla del ataque de la tribu mequí de los coraixíes, terminó con la rendición de los asaltantes, quienes habían sido ayudados por la tribu judía de Jaibar. Mahoma se sintió traicionado por los judíos con quienes había alcanzado un pacto y, como castigo, decidió aplicar la antigua ley hebrea del herem o anatema, es decir, juzgó a los judíos de acuerdo con el Deuteronomio: muerte para los varones adultos, esclavitud para niños y mujeres (Dt 20,10-16). Para comprender esta decisión, hay que tener en cuenta que Mahoma permitía a judíos y cristianos, al menos en asuntos internos, regirse por la Torá y el Evangelio, respectivamente (Corán 5, 44-48). Ibn Ishaq en su vida de Mahoma, 690-691, precisa que al menos setecientos judíos fueron decapitados. Este fue probablemente el episodio más violento y sanguinario de la vida de Mahoma, pero su dureza le proporcionó fama y fidelidades que antes eran dudosas, especialmente entre los beduinos de los alrededores de Medina. 
«Dios, ciertamente, os auxilió en Badr cuando erais humillados. ¡Temed a Dios! Quizás, así, seáis agradecidos. Cuando decías a los creyentes: "¿No os basta que vuestro Señor os refuerce con tres mil ángeles enviados abajo?» (Corán 3, 123-124).

"Quienes creen en Dios y en el último Día no te piden dispensa cuando de luchar con su hacienda y sus personas se trata. Dios conoce bien a quienes Le temen. Sólo te piden dispensa quienes no creen en Dios y en el último Día, aquéllos cuyos corazones están llenos de dudas y que, por dudar, vacilan. (...) Hay entre ellos quien dice: "¡Dispénsame y no me tientes!". Pero ¿es que no han caído ya en la tentación? La gehena, ciertamente, cercará a los infieles» (Corán 9, 44-45, 49).

\subsection{Aleyas «belicistas»}

Su número y su fuerza son suficientes para establecer que puede encontrarse ya en el Corán una doctrina relativa al yihad guerrero. Las más conocidas se extraen de la segunda sura. Algunas establecen sin duda alguna la licitud del yihad defensivo cuando se es atacado directamente por otros o cuando la propia fe se ve amenazada (Corán 2, 190-195; 8, 38-39; 9, 13-14; 22, 39-40). Los combates terminarán cuando cese la amenaza. El contexto de las aleyas que se reproducen a continuación puede ser probablemente la tregua de Hudayhiyya establecida con los mequíes con el fin de garantizar la peregrinación a la Kaaba y defenderse, proporcionadamente, de aquellos que atacasen a los musulmanes:

«Combatid por Dios contra quienes combatan contra vosotros, pero no os excedáis. Dios no ama a los que se exceden. Matadles donde deis con ellos, y expulsadles de donde os hayan expulsado. Tentar es más grave que matar. No combatáis contra ellos junto a la Mezquita Sagrada, a no ser que os ataquen allí. Así que, si combaten contra vosotros, matadles: ésa es la retribución de los infieles. Pero, si cesan, Dios es indulgente, misericordioso. Combatid contra ellos hasta que dejen de induciros a apostatar y se rinda culto a Dios. Si cesan, no haya más hostilidades que contra los impíos (Corán 2, 190-193).

«Les está permitido a quienes son atacados, porque han sido tratados injustamente. -Dios es, ciertamente, poderoso para auxiliarles-. A quienes han sido expulsados injustamente de sus hogares, sólo por haber dicho: "¡Nuestro Señor es Dios!" Si Dios no hubiera rechazado a unos hombres valiéndose de otros, habrían 
sido demolidas ermitas, iglesias, sinagogas y mezquitas, donde se menciona mucho el nombre de $\operatorname{Dios}^{25}$. Dios auxiliará, ciertamente, a quienes le auxilien. Dios es, en verdad, fuerte, poderoso» (Corán 22, 39-40).

No obstante, también pueden encontrarse otras aleyas que apuntan a extender la guerra contra los infieles, incluidos judíos ${ }^{26}$ y cristianos, de las proximidades, particularmente contra los mequíes (Corán 9, 73; 47, 4), incluso de una manera "permanente» hasta que se sometan a la ley del islam (lo que no implica necesariamente la conversión) y paguen el tributo o la indemnización conocida como jizyah (Corán 9, 29) 27.

«iProfeta! ¡Combate contra los infieles y los hipócritas, se duro con ellos! Su refugio será la gehena. ¡Qué mal fin...!» (Corán 9, 73).

"iCombatid contra quienes, habiendo recibido la Escritura, no creen en Dios ni en el último Día, ni prohíben lo que Dios y Su Enviado han prohibido, ni practican la religión verdadera, hasta que, humillados, paguen el tributo directamente!» (Corán 9, 29).

La sura novena probablemente fue revelada a Mahoma hacia el final de su vida, unos pocos años antes del inicio de las conquistas musulmanas, lo que explicaría la agresividad de los primeros musulmanes ${ }^{28}$. Su contenido relativo a los cristianos y judíos parece referirse expresamente a aquellos que no vivían coherentemente con su fe y moral y que traicionaron al Profeta vulnerando los pactos establecidos.

25 Es interesante destacar que aquí los edificios religiosos de judíos, cristianos y musulmanes aparecen descritos a un mismo nivel, como lugares donde igualmente se venera a Dios y que éste protege igualmente. Este aspecto también lo señala Dagli $(2015,1807)$.

26 Contra éstos, véase especialmente Corán 59, 1-17.

27 Dagli $(2015,1811)$ sostiene que ni el Profeta ni los primeros califas humillaron a los dhimmis mientras pagaran la indemnización (jizyah). En su opinión, los dhimmis o «pueblo de la alianza», generalmente judíos y cristianos, pero en la práctica también zoroástricos e hindúes, que pagaban la jizyah podían vivir bajo la legislación musulmana con total autonomía religiosa y no tenían obligación de contribuir a la protección militar del estado musulmán. Bonner $(2006,88-91)$ señala que, salvo excepciones, en términos generales se solía respetar el estatus de los dhimmis.

28 Cf. Cook $(2015,10)$. 


\section{Prescripciones coránicas sobre la guerra}

El Corán considera la guerra como un mal a evitar, aunque, según circunstancias como acaba de verse, la estima necesaria. Una vez que el conflicto bélico se hace inevitable o ha comenzado, éste debe seguir unas pautas establecidas. Sin embargo, hay que tener en cuenta que en ningún momento pretende el Corán ser un tratado militar ni exponer cómo debe ser el "arte» de la guerra. Pero de su lectura pueden extraerse unas pautas de comportamiento durante los conflictos bélicos sustentadas en principios religiosos. Las principales son las siguientes:

\subsection{Causas que legitiman el combate ${ }^{29}$}

a) En primer lugar, el Corán enseña que, si es posible, el conflicto debe ser evitado, de modo que si el considerado enemigo de Dios, el infiel, declina hacer la guerra y se inclina hacia la paz, hay que otorgársela:

«Si, al contrario, se inclinan hacia la paz, jinclínate tú también hacia ella! ¡Y confía en Dios! Él es Quien todo lo oye, Quien todo lo sabe» (Corán 8, 61; cf. 4, 90).

«Aléjate, pues, de ellos y di: “¡Paz!” ¡Van a ver...!» (Corán 43, 89).

No se dan razones de esto, pero se puede deducir del hecho del gran valor que otorga el Corán a la vida humana, que debe ser respetada en lo posible evitando matar al inocente:

«Por esta razón, prescribimos a los Hijos de Israel que quien matara a una persona que no hubiera matado a nadie ni corrompido en la tierra, fuera como si hubiera matado a toda la Humanidad. Y que quien salvara una vida, fuera como si hubiera salvado las vidas de toda la Humanidad» (Corán 5, 32) ${ }^{30}$

29 Pese a que en el islam clásico, como también sucede en otras religiones y culturas de la antigüedad, no se hace una distinción clara entre las causas justas para llegar a la guerra (jus ad bellum) y la manera justa de desempeñarse durante la misma (jus in bello), en el Corán pueden atisbarse al menos unos principios generales como los que se señalan a continuación. Actualmente, debido al influjo del derecho internacional, hay un incremento en los países musulmanes del interés por el ius ad bellum; sobre esto, véase Shadi (2017).

30 También la tradición rabínica judía planteaba la idea de que matar a un ser humano es como matar a toda la humanidad. Véase, por ejemplo, Abot de Rabbí Natán $\mathrm{XXXI}, 1$. 
Puede decirse, por tanto, que en el Corán el factor religioso es clave para valorar un conflicto armado: bien porque se combate contra el supuesto enemigo de Dios, bien porque se prohíbe la muerte del inocente cuya vida es protegida por el mismo Dios. En este sentido, cabe decir que este factor religioso introducido por Mahoma, en algunos aspectos «contracultural» en la Arabia de la época ${ }^{31}$, posibilita cierta «humanización» de la guerra al ponerle límites que eviten se convierta en algo caótico y destructor de vidas inocentes.

b) Se permite luchar en defensa propia (cf. Corán 2, 190; 22, 39; $26,227 ; 42,39)$ cuando se ha sido atacados injustamente o por razón de la propia fe:

«No son así los que creen, obran bien, recuerdan mucho a Dios y se defienden cuando son tratados injustamente. ¡Los impíos verán pronto la suerte que les espera!» (Corán 26, 227).

«(Los creyentes) se defienden cuando son víctimas de opresión» (Corán 42,39).

Pero combatir «por la causa de Dios» es un deber inexcusable para cualquier musulmán varón adulto que esté en condiciones. La siguiente aleya, cuyo contexto inmediato parece ser la expedición a Tabuk (9 H/631 d.C.), localidad próxima a la frontera con el Imperio bizantino, deja claro este deber:

"iCreyentes! ¿Qué os pasa? ¿Por qué, cuando se os dice: "¡ld a la guerra por la causa de Dios!", permanecéis clavados en tierra? ¿Preferís la vida de acá a la otra? Y ¿qué es el breve disfrute de la vida de acá comparado con la otra, sino bien poco...?» (Corán 9, 38).

Únicamente, además de mujeres y niños, los varones débiles, enfermos, ciegos, cojos o los que no tienen medios para armarse quedan exentos de este deber:

"Quedan exceptuados los oprimidos — hombres, mujeres y niños-, que no disponen de posibilidades y no son dirigidos por el Camino. A éstos puede que Dios les perdone. Dios es perdonador, indulgente» (Corán 4, 98-99; cf. 9, 91-92; 48, 17).

31 Piénsese, por ejemplo, en el infanticidio femenino practicado por algunas tribus beduinas en situaciones extremas y que Mahoma rechazó totalmente; cf. Corán 6, 151$152 ; 17,31 ; 81,8-9$. 
Esta lucha o combate por la fe debe durar hasta que se garantice que nadie obligará a los musulmanes a apostatar de su fe. Esto significa, implícitamente, que la finalidad no es exterminar al enemigo:

"Combatid contra ellos hasta que dejen de induciros a apostatar y se rinda todo el culto a Dios. Si cesan, Dios ve bien lo que hacen» (Corán 8, 39; cf. 2, 192-193).

c) No es deseable combatir durante el mes sagrado o de peregrinación anual y, por tanto, de tregua, pero, como ya se ha comentado con anterioridad, la inacción ante una situación de opresión es aún peor y tentar a perder la fe es peor que matar, de modo que, en estos casos, se debe combatir incluso durante los considerados meses sagrados (cf. Corán 2, 191-193. 217).

d) Los musulmanes tienen el deber de asistir a otros musulmanes que sean víctimas de agresión:

"¿Por qué no queréis combatir por Dios y por los oprimidos —hombres, mujeres y niños-, que dicen: "¡Señor! ¡Sácanos de esta ciudad [la Meca], de impíos habitantes! ¡Danos un amigo designado por Ti! ¡Danos un auxiliar designado por Ti!" ?» (Corán 4, 75).

Pero a su vez deben evitarse las rencillas internas entre musulmanes, buscando la reconciliación y, si fuera necesario, dominando al grupo opresor hasta que vuelva a la obediencia de Alá:

"Si dos grupos de creyentes combaten unos contra otros, ¡reconciliadles! Y, si uno de ellos oprime al otro, ¡combatid contra el opresor hasta reducirle a la obediencia de Dios! Y, cuando sea reducido, jreconciliadles de acuerdo con la justicia y sed equitativos! Dios ama a los que observan la equidad» (Corán 49, 9).

e) Está prohibido luchar con quienes se ha hecho un tratado o con quienes desean la paz:

«No aceptéis su amistad ni auxilio, a menos que sean aliados de gente con la que os una un pacto, o que vengan a vosotros con el ánimo oprimido por tener que combatir contra vosotros o contra su propia gente. Si Dios hubiera querido, les habría dado poder sobre vosotros y habrían combatido contra vosotros. Si se mantienen aparte, si no combaten contra vosotros y os ofrecen someterse, entonces no tendréis justificación ante Dios contra ellos» (Corán 4, 90). 
Sin embargo, si las alianzas o tratados han sido violados se debe combatir a los infractores:

«Pero, si violan sus juramentos después de haber concluido una alianza y atacan vuestra religión, combatid contra los jefes de la incredulidad. No respetan ningún juramento. Quizás, así, desistan» (Corán 9, 12; cf. 8, 58).

\subsection{Normas para el combate}

a) Aunque el Corán no señala expresamente qué personas por razón de sexo o edad no deben ser combatidas ${ }^{32}$, es taxativo exigiendo que deben evitarse los excesos durante el combate pues Alá no los desea:

"Combatid por Dios contra quienes combatan contra vosotros, pero no os excedáis ${ }^{33}$. Dios no ama a los que se exceden» (Corán 2, 190).

Por ello mismo, y si bien estas aleyas se refieren concretamente al asesinato más que a la lucha en combate, parece claro que la prohibición de matar a inocentes (Corán 6,$151 ; 17,33 ; 25,68$ ) puede extenderse a las situaciones de conflicto bélico, un ejemplo más de los límites que por motivos religiosos deben establecerse en tales circunstancias ${ }^{34}$ :

32 Sobre el tratamiento a los no combatientes y al enemigo vencido, véase, entre otros, Landau-Tasseron (2006) y García (2015). Las principales colecciones de hadices del siglo Ix d.C., tales como Sahîh Al-Bujâri y Sahîh Muslim, contienen un apartado dedicado al yihad, en el que especifican que está prohibido matar a mujeres y niños.

33 García (2009, 248-249) compara diversas traducciones del término lāta'tadū a idiomas europeos, tales como «no excederse», «no agredir», «no rebasar los límites» o «no trasgredir», que considera factibles, para subrayar que «lo auténticamente relevante es captar la forma en que los propios musulmanes han entendido, a lo largo del tiempo, las referencias fundamentales de sus creencias».

34 Por el contrario, el grupo yihadista Daesh en sus publicaciones en línea anima a practicar la brutalidad contra quienes considera infieles. Así, por ejemplo, el número 2 de su revista Rumiyah («Roma»), publicado en 2016, tiene un artículo con el significativo título: «Brutality and severity towars the kuffar», ilustrado con terribles fotografías de decapitaciones y mutilaciones. Curiosamente, no se apoya en citas del Corán, sino en la sira de Ibn Ishaq y en la historia de Rashid Khulafa. Diríase que algunas de estas imágenes son más poderosas por sí mismas que el texto que las acompaña. Resulta de interés el análisis que realizan Droogan y Peattie (2018) sobre la variedad temática de la revista Inspire del grupo terrorista Al Qaeda. 
«No matéis a nadie que Dios haya prohibido, sino con justo motivo. Si se mata a alguien sin razón, damos autoridad a su pariente próximo, pero que éste no se exceda en la venganza ${ }^{35}$. Se le auxiliará» (Corán 17, 33).

b) El Corán insiste en que el trato que debe darse entre musulmanes o creyentes debe ser amable y conciliador. Uno de los términos más utilizados para definir este trato es ihsam, que aparece unas cien veces y puede traducirse como «caridad» o "amabilidad». Comprende, entre otras cosas, generosidad, autocontrol y clemencia36. Consecuentemente, queda prohibido matar a otros musulmanes. Si se mata a otro musulmán por error, el responsable «deberá manumitir a un esclavo creyente y pagar el precio de sangre a la familia de la víctima, a menos que ella renuncie al mismo como limosna» (Corán 4,92 ). Si se hace premeditadamente, su destino final será la gehena o infierno:

«Y quien mate a un creyente premeditadamente, tendrá la gehena como retribución, eternamente. Dios se irritará con él, le maldecirá y le preparará un castigo terrible» (Corán 4, 93).

Esta prohibición tan tajante se vuelve contra los actuales terroristas yihadistas, pues la mayoría de las víctimas de sus atentados suelen ser musulmanes. Sin embargo, históricamente se han producido enfrentamientos entre musulmanes. Para ello, basta con declarar al otro como mal musulmán y, en definitiva, degradarlo a la condición de incrédulo. Si un líder musulmán tiene intención de declararle la guerra a una nación islámica, debe declarar primero a esta nación incrédula o atea, «impía» o «infiel», kafir en árabe. Cuando se declara kafir al otro, se vuelve legítima e inevitable la declaración de guerra, porque va dirigida contra los incrédulos (Samir 2003, 45) 37.

35 En la literatura bíblica este pariente próximo era el go'el o vengador de sangre. El mismo Yahvé aparece como el go'el de su pueblo Israel (cf. Is 41, 14; 43, 1. 14; 44, 6. 22-23; 47, 4; 48, 17. 20; 49, 26; 51, 10; 52, 9; 54, 5; 60, 16).

36 Véase Donner $(2007,302)$.

37 En este sentido, el grupo yihadista Daesh suele denominar takfir a los musulmanes que no comparten su interpretación del islam ni sus métodos violentos, como puede verse, por ejemplo, en el mencionado número 2 de la revista Rumiyah, donde el término aparece 39 veces. El número 7 de esta revista lleva el significativo título de «Establishing the Islamic State. Between the Prophetic Methodology and the Paths of the Deviants». 
c) Se debe luchar con la confianza puesta en Alá, pues Él ayuda en la lucha (Corán 9, 14) y está junto con los que le temen (Corán 9, 123):

"iCombatid contra ellos! Dios le castigará a manos vuestras y les llenará de vergüenza, mientras que a vosotros os auxiliará contra ellos, curando así los pechos de gente creyente» (Corán 9, 14).

d) No hay que ceder en el combate ni dar la espalda al enemigo (Corán 8, 15. 57) ni suplicar por la paz:

«¡No flaqueéis, pues, invitando a la paz, ya que seréis vosotros los que ganen! Dios está con vosotros y no dejará de premiar vuestras obras» (Corán 47, 35).

e) Los prisioneros de guerra deben ser bien tratados. Aunque, en aplicación de la antiquísima ley del talión, ya presente en el Código de Hammurabi (CH 196-205) y en la Torá judía (Ex 21, 23-25), algunas aleyas permiten que se castigue del mismo modo que uno ha sido castigado, se recomienda en lo posible la paciencia y el perdón:

«Si castigáis, castigad de la misma manera que se os ha castigado. Pero, si tenéis paciencia, es mejor para vosotros» (Corán 16, 126).

El tratamiento respetuoso de los prisioneros debe realizarse sin esperar nada a cambio, únicamente por cumplir la voluntad divina:

"Cuando sostengáis, pues, un encuentro con los infieles, descargad los golpes en el cuello hasta someterlos. Entonces, atadlos fuertemente. Luego, devolvedles la libertad, de gracia o mediante rescate, para que cese la guerra. Es así como debéis hacer. Si Dios quisiera, se defendería de ellos, pero quiere probaros a unos por medio de otros. No dejará que se pierdan las obras de los que hayan caído por Dios» (Corán 47, 4) ${ }^{38}$.

«Por mucho amor que tuvieran al alimento, se lo daban al pobre, al huérfano y al cautivo: "Os damos de comer sólo por agradar a Dios. No queremos de vosotros retribución ni gratitud» (Corán 76, 8-9).

38 Suele considerarse que esta aleya abroga la de Corán 8, 67, que parece prohibir la toma de prisioneros: «No está bien que un profeta tenga cautivos mientras no someta en la tierra. Vosotros queréis lo que la vida de acá ofrece, en tanto que Dios quiere la otra vida. Dios es poderoso, sabio». Cf. Landau-Tasseron $(2003,42)$. 
Cabe la opción de que aquellos cautivos que se conviertan al islam puedan ser liberados, si bien puede quedar la duda de que dicha conversión haya sido sincera:

«iProfeta! Di a los cautivos que tengáis en vuestro poder: "Si Dios encuentra bien en vuestros corazones, os dará algo mejor de lo que se os ha quitado y os perdonará. Dios es indulgente, misericordioso". Y si quieren traicionarte, ya antes traicionaron a Dios. Y Él ha dado poder sobre ellos. Dios es omnisciente, sabio» (Corán 8, 70-71).

Sin embargo, no siempre se hacen prisioneros, dado que no hay piedad con los «hipócritas», es decir, los musulmanes o creyentes de palabra pero remisos e infieles de corazón (Corán 33, 60-61) ni con «quienes hacen la guerra a Dios» (Corán 5,33 ) y no se arrepienten antes de caer en manos musulmanas. La suerte que les espera, en esta vida y en la otra, es terrible. En estos casos la violencia humana terrenal y la «violencia escatológica», prerrogativa de Dios, van de la mano:

«Si los hipócritas, los enfermos de corazón y los agitadores de la ciudad no cesan, hemos de incitarte contra ellos y pronto dejarán tu vecindad. Malditos, serán capturados y muertos sin piedad donde quiera que se dé con ellos» (Corán 33, 60-61)39.

«Retribución de quienes hacen la guerra a Dios y a Su Enviado y se dan a corromper en la tierra: serán muertos sin piedad, o crucificados, o amputados de manos y pies opuestos ${ }^{40}$, o desterrados del país. Sufrirán ignominia en la vida de acá y terrible castigo en la otra» (Corán 5, 33).

Lo mismo puede decirse de los «asociadores», politeístas o quienes no admiten la absoluta unicidad de Dios, pero se puede acoger a quienes soliciten asilo y enseñarles el islam:

"Cuando hayan transcurrido los meses sagrados, matad a los asociadores donde quiera que les encontréis. ¡Capturadles! ¡Sitiadles! ¡Tendedles emboscadas por todas partes! Pero si se arrepienten,

39 Estas aleyas probablemente se estén refiriendo de manera particular a determinados musulmanes medineses.

40 Asad (2001, 145, nota 44) hace el siguiente comentario a esta aleya: «En árabe clásico, "cortar las manos y los pies" es sinónimo de "destruir el poder de alguien", y es posible que este sea el sentido que se quiere dar aquí a esta expresión. Podría significar también "que sean mutilados", bien física o metafóricamente —como en el uso (metonímico) de la expresión "que sean crucificados", en el sentido de "que sean torturados"—». 
hacen la azalá y dan el azaque, entonces ¡dejadles en paz! Dios es indulgente, misericordioso. Si uno de los asociadores te pide protección concédesela, para que oiga la palabra de Dios. Luego, facilítale la llegada a un lugar en que esté seguro. Es que son gente que no sabe» (Corán 9, 5-6).

De todas formas, conviene matizar que Corán 9, 5 no se refiere a todos los "asociadores» de todos los lugares y tiempos, sino que su contexto inmediato alude a aquellos que no cumplieron con el mencionado pacto o alianza de Hudaybiyya establecido en el campo de batalla (cf. Corán 9, 4), y, en su conjunto, se refiere a los paganos árabes. No obstante, esta aleya, conocida como el "verso de la espada», pronto fue utilizada por algunos juristas musulmanes para proclamar una yihad universal contra todos los no musulmanes ${ }^{41}$.

f) La obtención del botín es legítima y un derecho. Sin embargo, el Corán advierte contra aquellos ambiciosos que, con el fin de conseguir botín, rápidamente juzgaban a los otros como no creyentes y les declaraban la guerra:

"iCreyentes! cuando acudáis a combatir por Dios, cuidado no digáis al primero que os salude: "¡Tú no eres creyente!", buscando los bienes de la vida de acá. Dios ofrece abundantes ocasiones de obtener botín. Vosotros también erais así antes y Dios os agració! ¡Cuidado, pues, que Dios está bien informado de lo que hacéis!» (Corán 4, 94).

El botín se reparte en cinco partes, una de las cuales es para Mahoma y las otras cuatro para los combatientes (Corán 8, 1, 41, 69):

«Sabed que, si obtenéis algún botín, un quinto corresponde a Dios, al enviado y a sus parientes, a los huérfanos, a los pobres y al viajero, si creéis en Dios y en lo que hemos revelado a nuestro siervo el día del Criterio, el día que se encontraron los dos ejércitos. Dios es omnipotente» (Corán 8, 41).

41 Este «verso de la espada» es utilizado y mal interpretado recurrentemente por el Daesh para legitimar sus actos terroristas. Véase, por ejemplo, el artículo «The Revival of Slavery before the Hour» en el número 4 de la revista Dabiq publicado en 2014. En sus revistas el grupo yihadista recopila y selecciona diversas citas del Corán, de la sira y de los hadices, pero obviando el contexto histórico en el que surgieron y toda exégesis moderna de las mismas. 
g) Aquellos que luchan por Dios, aunque mueran en el combate, recibirán de premio la vida venturosa en el Jardín paradisíaco. Como ya se ha apuntado con anterioridad, en el Corán ya se esboza la teología del martirio en combate que será desarrollada por la tradición posterior:

« ¿Que quienes cambian la vida de acá por la otra combatan por Dios! A quien, combatiendo por Dios, sea muerto o salga victorioso, le daremos una magnífica recompensa» (Corán 4, 74) ${ }^{42}$.

"¿No has visto a aquéllos a quienes se dijo: "¡Deponed las armas! ¡Haced la azalá y dad el azaque!"? Cuando se les prescribe el combate, algunos de ellos tienen tanto miedo de los hombres como deberían tener de Dios, o aún más, y dicen: "¡Señor! ¿Por qué nos has ordenado combatir? Si nos dejaras para un poco más tarde..." Di: "El breve disfrute de la vida de acá es mezquino. La otra vida es mejor para quien teme a Dios. No se os tratará injustamente en lo más mínimo"» (Corán 4, 77).

«Dios ha comprado a los creyentes sus personas y su hacienda, ofreciéndoles, a cambio el Jardín. Combaten por Dios: matan o les matan. Es una promesa que le obliga, verdad, contenida en la Torá, en el Evangelio y en el Corán. Y ¿quién respeta mejor su alianza que Dios? ¡Regocijaos por el trato que habéis cerrado con Él! ¡Ése es el éxito grandioso!» (Corán 9, 111).

Resulta curioso que esta última aleya pretenda legitimarse también en las escrituras sagradas de judíos y cristianos. Sin embargo, esta legitimación no es tan evidente. El texto de la Torá (o Pentateuco) al que se alude no es claro: podría ser Dt 20, 1-4, pero sin referencia a premio alguno de carácter escatológico. En cuanto a los Evangelios, éstos carecen de incitaciones al combate o a la guerra por Dios. Dentro del Nuevo Testamento, únicamente cabría pensar en el simbólico combate escatológico de Ap 19, 11-21. En todo caso, hay que tener en cuenta que casi con toda seguridad Mahoma no conoció la Biblia de judíos y cristianos, y es muy probable que su conocimiento de ambas religiones fuera muy fragmentario.

42 Como señala Burki (2011, 592), los grupos yihadistas suelen apoyarse en esta aleya para legitimar sus "operaciones de martirio» suicidas, pero la aleya en sí no sugiere ningún autosacrificio violento realizado por la propia mano. Más aún, los terroristas obvian la aleya 29 de la misma sura, que exhorta a los creyentes a no matarse unos a otros. 


\section{Reflexiones conclusivas}

Para el texto fundacional más importante del islam, el Corán, el conflicto bélico es una realidad no deseable pero que en ocasiones hay que asumir como inevitable. En diversas situaciones el propio Mahoma se vio obligado a combatir y a ejercer ciertas formas de violencia que hoy nos parecen reprochables. Mahoma no fue un «pacifista a ultranza», y probablemente no hubiera podido serlo en el contexto histórico y cultural que le tocó vivir si es que pretendía llevar a buen puerto su proyecto religioso de claras consecuencias políticas. A diferencia, entre otros, del Buda y de Jesús de Nazaret, precursores de lo que hoy llamaríamos la «no violencia activa», Mahoma tuvo que organizar militarmente a la comunidad musulmana para defenderla de sus enemigos. De lo contrario, su supervivencia hubiera sido muy difícil. Como señala Sohail H. Hashmi:

«En resumen, la posición del Corán frente a la guerra y la paz puede calificarse de realismo idealista. La existencia humana no se caracteriza ni por un incesante combate, ni por una paz real, sino por una tensión continuada entre los dos. Las sociedades existen en un equilibrio precario entre ambos extremos. El interminable reto humano, el jihad fi sabil Allah (la lucha en la senda de Al-láh), debe mitigar la posibilidad de guerra para fortalecer la paz» (Hashmi 2009, 15).

Este «realismo idealista», como lo denomina Hashmi, explicaría la ambivalencia o ambigüedad que puede encontrarse en el Corán al contrastar las aleyas «pacifistas» con las «belicistas», las cuales sólo se pueden comprender atendiendo al contexto histórico que influyó sobre ellas. Pero asumir la realidad del conflicto bélico no impidió a Mahoma instaurar unas pautas de comportamiento ante el mismo que superaron éticamente las costumbres guerreras de la época. Mostró un humanitarismo de base religiosa que evitó la despersonalización o deshumanización del "otro», y que se reflejó en una serie de normas tales como, entre otras, el deber de evitar en lo posible el combate, las prohibiciones de ensañarse o matar a inocentes y musulmanes, el deber de proteger a los débiles o el trato respetuoso a los prisioneros de guerra. La creencia en el Dios único y universal llevaba consigo el deber de frenar la violencia interhumana, y cuando ésta se entendía inevitable, de ejercerla limitada y controladamente con el fin de evitar que se volviera indiscriminada y caóticamente destructora.

Esta actitud ante la violencia y el conflicto bélico del fundador del islam invita a sus seguidores a actuar de manera similar en situaciones 
de conflicto, particularmente cuando la comunidad musulmana pueda sentirse amenazada, pero también deslegitima al terrorismo yihadista que incumple las pautas éticas y religiosas mencionadas y que desvirtúa la imagen de Dios ofrecida en el Corán.

Una última consideración. Es fundamental reconocer que en los «libros sagrados» de las grandes religiones monoteístas hay textos que legitiman ciertas formas de violencia que son inaceptables para nuestros actuales códigos éticos, presumiblemente celosos de los derechos humanos. Obviar o esconder la existencia de tales textos, con el fin de ofrecer una imagen idílica de la propia religión, posibilita que hermeneutas fundamentalistas, de interpretación literalista y ahistórica, los hagan suyos y conviertan su violencia en imperecedero imperativo divino. Reconocer la existencia de esos textos e interpretarlos adecuadamente atendiendo a su contexto histórico y cultural ayuda a deconstruir el discurso del fundamentalismo ${ }^{43}$. Lo que vale tanto para el Corán como para la Biblia judía y cristiana.

\section{Bibliografía}

An-Na'im, Abdullahi Ahmed. 1990. "Corán, «sharia» y derechos humanos. Fundamentos, fallos y perspectivas". Concilium 228: 239-249.

Arendonk, C. van y Gimaret, D. 1995. "Salam". En The Encyclopaedia of Islam, vol. VIII, editado por E. van Donzel, B. Lewis y Ch. Pellat, 915-918. Leiden: E.J. Brill.

Asad, Muhammad. 2001. El mensaje del Qur'an. Traducción del Árabe y Comentarios Muhammad Asad. Fuente de Arriba-Almodóvar del Río (Córdoba): Junta Islámica-Centro de Documentación y Publicaciones.

Bonner, Michael. 2006. Jihad in Islamic History. Doctrines and Practice. Princeton: Princeton University Press.

43 En este sentido, cabe citar la fatua emitida el 10 de marzo de 2005 por la Comisión Islámica de España condenando el terrorismo y al grupo Al Qaida. Se trata de un documento valioso y bien elaborado que deslegitima el terrorismo yihadista con textos del Corán y de la sunna o tradición. Sin embargo, no menciona otros textos de las mismas fuentes en los que se apoyan los terroristas. Uno de los textos coránicos que más se han visto reproducidos en los medios de comunicación tras los últimos atentados yihadistas en países europeos ha sido el de Corán 5, 32, que afirma que quien mata a un inocente mata a la humanidad entera y quien salva una vida salva a la humanidad entera. Lo que no se dice es que, tras esta bellísima aleya, viene otra que amenaza con la ejecución, crucifixión, amputación y destierro, además de con el castigo en el más allá, a quienes combatan a los musulmanes. Este texto también es coránico y, como otros, requiere ser explicado para evitar su manipulación por los fundamentalistas. 
Borreguero, Eva. 2004. "Paz y violencia en el islam". En 10 palabras clave sobre paz y violencia en las religiones, dirigido por Juan José Tamayo, 135158. Estella: Verbo Divino.

Burki, Shireen K. 2011. "Haram or Halal? Islamists' Use of Suicide Attacks as «Jihad»". Terrorism and Political Violence 23: 582-601.

Catalá, Santiago. 2010. "La violencia en las religiones abrahámicas". En Violencia e Islam. La violencia en y contra el Islam en el Derecho Internacional, coordinado por Agustín Motilla, 15-70. Granada: Comares.

Cook, David. 2015. Understanding Jihad. Oakland, Ca.: University of California Press.

Cortés, Julio. 1992. El Corán. Barcelona: Herder.

Dagli, Caner K. 2015. "Conquest and Conversion, War and Peace in the Quran". En The Study Quran. A New Translation and Commentary, editado por Seyyed Hussein Nasr, 1805-1817. Nueva York: Harper One.

Donner, Fred. 2002-2003. "From Believers to Muslims: Confessional SelfIdentity in the Early Islamic Community". Al-Abhath. Journal of the Faculty of Arts and Sciences American University of Beirut 50-51: 9-53.

Donner, Fred. 2007. "Fight for God- But Do So with Kindness: Reflections on War, Peace, and Communal Identity in Early Islam". En War and Peace in the Ancient World, editado por Kurt A. Raaflaub, 297-311. Oxford: Blackwell.

Droogan, Julian y Peattie, Shane. 2018. "Reading jihad: Mapping theshifting themes of Inspire magazine". Terrorism and Political Violence 30: 684717.

Faizer, Rizwi (ed.). 2011. The Life of Muhammad. Al-Waqidi's Kitab alMaghazi. Londres: Routledge.

Fine, Jonathan. 2015. Political Violence in Judaism, Christianity, and Islam. From Holy War to Modern Terror. Nueva York: Rowman \& Littlefield.

Firestone, Reuven. 1999. Jihād. The Origin of Holy War in Islam. Oxford: Oxford University Press.

Flori, Jean. 2004. Guerra santa, yihad, cruzada. Violencia y religión en el cristianismo y el Islam. Granada: Universidad de Granada-Universitat de Valéncia.

García Sanjuán, Alejandro. 2009. "Bases doctrinales y jurídicas del yihad en el derecho islámico clásico (siglos VIII-XIII)". Clio \& Crimen 6: 243-277.

García Sanjuán, Alejandro. 2015. "Tratamiento del enemigo vencido en la doctrina clásica malikí (ss. IX-XII)". En Cristãos contra muçulmanos na Idade Média peninsular: bases ideológicas e doutrinais de uma confrontação: (séculos X-XIV) / Cristianos contra musulmanes en la Edad Media peninsular: bases ideológicas y doctrinales de una confrontación: (siglos X-XIV), coordinado por Carlos de Ayala Martínez e Isabel Cristina F. Fernandes, 95-113. Lisboa: Edições Colibri, Universidade Autónoma de Madrid.

Guillaume, Alfred. 2015. The Life of Muhammad. A Translation of Ishâq's Sirat Rasûl Alláh. Oxford: Oxford University Press.

Gutiérrez Espada, Cesáreo. 2009. "Sobre el concepto de yihad". Athena Intelligence Journal 4: 189-214. 
Hallaq, Wael B. 2009. Shari'a. Theory, Practice, Transformations. Cambridge: Cambridge University Press.

Hashmi, Sohail H. 2009. "A propósito de la ética islámica sobre la guerra y la paz". En Múltiple yihad múltiple: consideraciones islámicas en torno al esfuerzo individual y la lucha colectiva, editado por Sohail H. Hashmi, Sohail, Reza Shah-Kazemi y otros, 7-41. Barcelona: Oozebap.

Heck, Paul L. 2004. "Jihad Revisited". Journal of Religious Ethics 32: 95-128. Huech, Bahige Mella. 2017. El Corán: Interpretación al español actual. Barcelona: Liga Islámica para el Diálogo y la Convivencia en España Consestruc-Editions.

Khadduri, Majid. 1955. War and Peace in the Law of Islam. Baltimore: The Johns Hopkins Press.

Landau-Tasseron, Ella. 2003. "Jihad". En Encyclopaedia of the Qur'an, vol. III, editado por Jane Dammen, 35-42. Leiden-Boston: McAuliffe Brill.

Landau-Tasseron, Ella. 2006. " "Non-Combatants» in Muslim Legal Thought". Research Monographson the Muslim World, Series No 1, Paper No 3: $1-25$.

López Pita, Paulina. 2009. "La guerra en el Corán y en la tradición musulmana". Revista de Historia Militar LIII-Número Extraordinario (Guerra santa. Guerra justa): 141-176.

Paradela Alonso, Nieves. 2001. "Belicismo y espiritualidad: una caracterización del yihad islámico". Militarium Ordinum Analecta 5: 653-667.

Peters, Rudolph. 1979. Islam and Colonialism. The Doctrine of Jihad in Modern History. La Haya: Mouton Publishers.

Reinares, Fernando y García-Calvo, Carola. 2016. Estado Islámico en España. Madrid: Real Instituto Elcano.

Rippin, Andrew. 2016. "Reading the Qur'an on jihad: Two Early Exegetical Texts". En Violence in Islamic Thought from the Qur'an to the Mongols, editado por Robert Gleave e István Kristó-Nagy, 33-48. Edinburgo: Edinburgh University Press.

Samir, Khalii. 2003. Cien preguntas sobre el Islam. Una entrevista a Samir Khalil Samir realizada por Giorgio Paolucci y Camille Eid. Madrid: Ediciones Encuentro.

Shadi, Heydar (ed.). 2017. Islamic Peace Ethics. Legitimate and Illegitimate Violence in Contemporary Islamic Thought. Baden-Baden: NomosAschendorff Verlag.

Venet, Juan. 2010. El Corán. Introducción, traducción y notas. Barcelona: Planeta. 


\section{Copyright}

Deusto Journal of Human Rights / Revista Deusto de Derechos Humanos is an Open Access journal; which means that it is free for full and immediate access, reading, search, download, distribution, and reuse in any medium only for non-commercial purposes and in accordance with any applicable copyright legislation, without prior permission from the copyright holder (University of Deusto) or the author; provided the original work and publication source are properly cited (Issue number, year, pages and DOI if applicable) and any changes to the original are clearly indicated. Any other use of its content in any medium or format, now known or developed in the future, requires prior written permission of the copyright holder.

\section{Derechos de autoría}

Deusto Journal of Human Rights / Revista Deusto de Derechos Humanos es una revista de Acceso Abierto; lo que significa que es de libre acceso en su integridad inmediatamente después de la publicación de cada número. Se permite su lectura, la búsqueda, descarga, distribución y reutilización en cualquier tipo de soporte sólo para fines no comerciales y según lo previsto por la ley; sin la previa autorización de la Editorial (Universidad de Deusto) o la persona autora, siempre que la obra original sea debidamente citada (número, año, páginas y DOI si procede) y cualquier cambio en el original esté claramente indicado. Cualquier otro uso de su contenido en cualquier medio o formato, ahora conocido o desarrollado en el futuro, requiere el permiso previo por escrito de la persona titular de los derechos de autoría. 